\title{
A argumentação de Kirzner sobre a publicidade de diante de dois auditórios: Escola Neoclássica e subjetivismo radical
}

\author{
Lucas Casonato 1 \\ Eduardo Angeli ${ }^{2}$
}

\section{Resumo}

Este artigo discute como Kirzner moldou sua argumentação acerca da publicidade na teoria econômica em diferentes momentos da carreira, embora suas ideias sobre o tema tenham permanecido as mesmas. Explica-se que esta diferenciação argumentativa resultou da existência de dois públicos consecutivos a que Kirzner se dirigiu, a Escola Neoclássica e o Subjetivismo Radical. A existência desses dois grupos fez com que o autor alterasse sua defesa da teoria misesiana para a propaganda enquanto ferramenta de concorrência empresarial no processo de mercado. Conclui-se que Kirzner se direcionou a suas audiências na tentativa de influenciá-las, mas sem ter buscado se incluir entre tais grupos, usando termos comuns a esses auditórios para demarcar sua posição diferenciada com relação a eles.

\section{Palavras-chave}

Israel Kirzner; Escola Austríaca; Publicidade.

\begin{abstract}
This article discusses how Kirzner shaped his argument about advertising in economic theory at different times in his career, although his ideas on the topic have remained the same. It is explained that this argumentative differentiation resulted from the existence of two consecutive audiences that Kirzner addressed, the Neoclassical School and Radical Subjectivism. The existence of these two groups made the author change his defense of the Misesian theory of advertising as a tool for entrepreneurial competition in the market process. It is concluded that

- Os autores agradecem a Armando Dalla Costa, Fabio Barbieri, Felipe Almeida, Ramón Fernández e a três pareceristas anônimos pelas valiosas críticas e sugestões, eximindo-os dos erros e omissões. O presente trabalho foi realizado com apoio da Coordenação de Aperfeiçoamento de Pessoal de Nível Superior - Brasil (CAPES) - Código de Financiamento 001.

1 Professor - Pontifícia Universidade Católica do Paraná (PUCPR) - Departamento de Economia End.: Rua Imaculada conceição, 1.155 - Prado Velho - CEP: 80215-901 - Curitiba - PR - Brasil. E-mail: casonato.economia@gmail.com - ORCID: https://orcid.org/0000-0003-1280-3049.

2 Professor - Universidade Federal do Paraná (UFPR) - End.: Avenida Prefeito Lothário Meissner, 632 Jardim Botânico - CEP: 80210-170 - Curitiba - PR - Brasil - E-mail: angeli@ufpr.br

ORCID: https://orcid.org/0000-0001-6676-9267

Recebido: 24/05/2020. Aceito: 19/06/2021.

Editor Responsável: Rogério Arthmar
\end{abstract}

(c) (i) (\$) Esta obra está licenciada com uma Licença Creative Commons Atribuição-Não Comercial 4.0 Internacional. 
Kirzner addressed his audiences in an attempt to influence them, but without having sought to be included among such groups because he uses terms common to these audiences as a way of demarcating his different position to them.

\section{Keywords}

Israel Kirzner; Austrian School; Advertising.

\section{JEL Classification}

B25; B31; B53.

\section{Introdução}

Em meados da década de 1970 a Escola Austríaca ressurgiu no ambiente acadêmico da Economia. Isso ocorreu após um período de mais de duas décadas sendo considerada relegada à História do Pensamento Econômico ou completamente absorvida pelo mainstream da profissão (Boettke, 1995, 134). ${ }^{1}$

Esse fenômeno de recuperação da Escola Austríaca, conhecido como Austrian Revival (Vaughn, 1994, 92-93), teve várias de suas causas apontadas na literatura econômica. Entre elas, diversas destacam o protagonismo de Israel Kirzner, então professor na New York University, cujo doutorado, ainda na década de 1950, havia sido orientado por Mises na mesma instituição (Kirzner, 1997a, 8; Boettke e Sautet, 2009, xiv).

A liderança de Kirzner na recuperação da Escola Austríaca é explicada, em boa medida, porque ele reconheceu e foi reconhecido como alguém que tomou como missão profissional levar as ideias misesianas para os demais economistas (Vaughn, 1994, 5; Kirzner, 1997b, 1; Boettke, 2014, 234). Em entrevista a Boehm $(1992,95)$, Kirzner afirmou ter feito esse esforço por ter percebido uma barreira de comunicação entre aquilo que Mises e Hayek propuseram e o entendimento disso pelo restante da profissão. Para Garrison (2002, 343), a carreira de Kirzner é marcada pela tradução e avanço na agenda de pesquisa de Mises.

1 Embora, segundo Vaughn (1994, 93-103), datem desse período contribuições seminais que ajudaram no ressurgimento do Austrianismo na década de 1970. 
Observada de uma perspectiva histórica, a obra de Kirzner revela que ele é um acadêmico assíduo na busca por participar dos mais diversos debates, engajado em mostrar o ponto de vista Austríaco sobre os temas que estiveram em pauta. Por exemplo, Boettke e Sautet (2009, xiv-v) mostraram que o primeiro livro de Kirzner, "The Economic Point of View", buscava recuperar os microfundamentos da Economia que teriam sido deixados de lado com a revolução Keynesiana. Em outro caso, Jakee e Spong $(2003,478)$ situaram as primeiras publicações de Kirzner na discussão metodológica sobre as limitações dos modelos econômicos que não permitiam mudanças endógenas. Já Boettke e Sautet (2010, x) perceberam o terceiro livro de Kirzner, "Essays on Capital", como tentativa de incluir as ideias de Mises na discussão da "Controvérsia de Cambridge". ${ }^{2}$

De fato, é possível atestar a atitude proativa de Kirzner em se inserir nesses debates, assim como em outros. No seu quarto e principal livro, "Competition and Entrepreneurship", o autor mencionou como motivação do trabalho o contexto de retomada das discussões microeconômicas sobre a teoria dos preços (Kirzner, 2013 [1973], ix). Quando da publicação de seu sétimo livro, "Discovery, Capitalism and Distributive Justice", Kirzner explicitou sua intenção de rever as diferentes posições no debate da época sobre justiça distributiva com base em um posicionamento Austríaco sobre o funcionamento do mercado (Kirzner, 2016 [1989], 3). No oitavo livro, "The Meaning of Market Process", publicado em meio ao debate com o lado mais subjetivista entre os seguidores da Escola Austríaca, Kirzner buscou mostrar a existência teórica de um estado de equilíbrio e a tendência a ele (Kirzner, 1992b, ix).

Dentre os debates em que é possível encontrar a participação kirzneriana, a literatura deu maior ênfase a este interno à Escola Austríaca na década de 1980, sobre a possibilidade de uma tendência ao equilíbrio na teoria econômica. Esse episódio, em que Kirzner e Ludwig Lachmann figuraram como protagonistas, é caracterizado por diferentes visões acerca da Moderna Escola Austríaca que tomava forma no período posterior ao Revival (Vaughn, 1992, 251; 1994, 8-9 e 127; 2000, 42; Barbieri, 2001, 118-119; 2008, 216). ${ }^{3}$

2 Conquanto essa não tenha sido a intenção original na época da primeira publicação do material, na década de 1960, como afirmado pelo próprio Kirzner (e.g. Boettke e Sautet, 2018, 760).

3 Lachmann foi um dos economistas mais importantes para a Escola Austríaca no último quarto do século XX, por ter ajudado a desenvolver o pensamento Austríaco durante o período do Revival e por ter debatido sobre a teoria do processo de mercado com Kirzner ao longo das décadas de 1970 e 1980. No começo da década de 1990, em um artigo sobre as diferentes visões acerca da ordem econômica, Vaughn $(1992,251)$ situou sua contribuição como reflexo do debate corrente à época entre Kirzner 
Como mostraram Korsgaard et al. (2016, 869), quando Kirzner associou sua visão do processo de mercado à teoria da Economia Neoclássica, o fez com ênfase no argumento de que ambas admitem um estado de equilíbrio para o qual a economia converge. O que, segundo Jakee e Spong (2003, 476-477), foi justamente o ponto de divergência que incitou as discussões entre os seguidores da Escola Austríaca nos anos 1980. Nessa discussão, Kirzner se destacou por posicionar sua interpretação da teoria Austríaca entre as duas visões que considerou extremas para alguns aspectos da teoria econômica, quais sejam, a Economia Neoclássica e o Subjetivismo Radical. $^{4}$

A década de 1980 pode ser considerada um marco para os trabalhos de Kirzner, porque nesse período se verifica o surgimento de uma nova forma de argumentação do autor em defesa da teoria da atividade empresarial. Essa alteração já foi percebida na literatura, explicada como forma de aproximação ao Subjetivismo Radical (Caldwell, 1984, 1235). O motivo da nova postura também é conhecido, provocado pela discussão, como indicado acima, entre membros da Escola Austríaca acerca da tendência ao equilíbrio, ilustrada pelo debate entre dois de seus expoentes, Kirzner e Lachmann (Vaughn, 1992, 251; 1994, 137; 2000, 42; Barbieri, 2001, 118119; 2008, 216; Jakee e Spong, 2003, 476-477).

Se esse período é interpretado com base no contexto do pós-Revival da Escola Austríaca, em que existiram diferentes tentativas de definição de uma teoria Austríaca, é possível supor que a mudança argumentativa de Kirzner possa ser compreendida como uma reação a elas, bem como uma tentativa de sustentar sua própria interpretação das ideias Austríacas. Este artigo defende tal interpretação, mostrando como Kirzner moldou sua argumentação acerca de um tema sobre o qual escreveu em diferentes momentos da carreira. No caso, estuda-se a posição kirzneriana a respeito do papel da publicidade na teoria econômica, pretendendo uma maior

e Lachmann. Em Vaughn $(1994,139)$ esses autores foram colocados como líderes acadêmicos do Revival que poderiam ser diferenciados, respectivamente, por sua atitude de aproximação ou afastamento em relação à Economia Neoclássica. Barbieri (2001, 36; 2008, 215-216) associou essa tensão à tentativa de solução do problema hayekiano sobre o conhecimento a que ambos teriam se dirigido. Esse "problema do conhecimento" se refere à indagação sobre como as informações disponíveis aos agentes no mundo real convergem para o conjunto específico, em termos de disseminação e conteúdo, que permite a coordenação no mercado - equilíbrio econômico.

4 O termo "Subjetivismo Radical" faz referência a um movimento na Economia que enfatiza a incerteza no ambiente econômico e o caráter criativo das decisões humanas, propondo maior subjetividade na interpretação dos fenômenos econômicos ao ponto de permitir o abandono da ideia de um estado de equilíbrio na teoria do processo de mercado (e.g. Vaughn, 1994, 114 e 134; Barbieri, 2001, 12 e 59; 2008, 220 e 228). 
compreensão de como Kirzner procurou estabelecer diálogo com dois auditórios distintos, a Escola Neoclássica e o Subjetivismo Radical.

\section{Kirzner e o papel do equilíbrio na teoria econômica}

A visão de Kirzner sobre o processo de mercado admite a existência de uma tendência ao equilíbrio, também aceita na Economia Neoclássica, mas rejeitada pelo Subjetivismo Radical. Ao mesmo tempo, ao se referir ao equilíbrio, Kirzner aponta que esse é um resultado futuro cujas condições no presente são indeterminadas. Com isso, o pensamento kirzneriano acredita se contrapor à teoria Neoclássica sobre o funcionamento dos mercados, porque esta estaria centrada em posições de equilíbrio previamente conhecidas, para as quais seria possível descrever as condições suficientes de ocorrência. Nisso, Kirzner se vê mais próximo do Subjetivismo Radical, que na interpretação kirzneriana postula a incapacidade de previsão das condições futuras da economia, já que estas seriam necessariamente formadas por ações criativas imprevisíveis. Desta forma, Kirzner se apropria de um termo central à Economia Neoclássica para traduzir sua tese da atividade empresarial sobre o funcionamento do mercado, com o que aborda o corpo principal da profissão.

É possível recuperar de Kirzner (2015a [1985], 144) como as interpretações da Economia Neoclássica e do Subjetivismo Radical podem ser consideradas extremas e opostas, refletindo discordâncias sobre a possibilidade de uma propensão econômica à coordenação, ilustradas pelo papel atribuído ao empresário no sistema econômico: (i) como agente reativo, respondendo automaticamente às variações nas condições do mercado Economia Neoclássica; ou (ii) como promotor espontâneo de novidades no mercado, responsável por modificar de maneira inédita as condições existentes - Subjetivismo Radical.

Na visão kirzneriana sobre a Economia Neoclássica, o papel do empresário é fornecer um serviço no sistema econômico, qual seja, o de alocar os recursos de maneira condizente com a situação de equilíbrio. Para esta atividade existe um mercado, definido por suas respectivas curvas de oferta e demanda, já que o serviço prestado aparece como um bem econômico escasso. Portanto, nenhuma teoria nova é necessária para lidar com a função 
empresarial, já que o próprio modelo Neoclássico seria capaz de explicá-la (Kirzner, 2015a [1985], 144-145). Seguindo o pensamento kirzneriano, como o empresário da teoria Neoclássica decide da mesma forma que os demais tomadores de decisão, o resultado agregado das escolhas individuais sempre permite a convergência para o estado de equilíbrio.

Já na interpretação kirzneriana sobre o Subjetivismo Radical, a função empresarial é colocada como elemento unânime a todo processo decisório, de modo que cada ação individual manifesta a capacidade criativa do agente econômico. Então, essa decisão criativa pode ser independente das condições em que são tomadas, de modo que a escolha feita pelo indivíduo pode ser, com relação ao ambiente em que ocorre, totalmente indeterminada. ${ }^{5}$ Com isso, pode não existir uma característica entre duas ou mais decisões que permita relacioná-las, impedindo sua integração sob um mesmo fenômeno econômico, o que bloqueia a possibilidade de serem consideradas de maneira unificada em uma construção teórica (Kirzner, 2015a [1985], 145-146). Nessa leitura de Kirzner, o mercado fica incapaz de promover regularidades sistemáticas em direção ao estado de equilíbrio, tese defendida pelo Subjetivismo Radical.

Para Kirzner (2015a [1985], 146), se a escolha de uma explicação para o papel do empresário é confinada a essas duas possibilidades, fica-se: (i) por um lado, sem explicações para o surgimento de novidades genuínas; ou, (ii) por outro, incapaz de admitir uma teoria que explique a direção das ações empresariais, relegando seus resultados futuros à total incerteza.

Pode-se compreender a partir de Kirzner (2015b [1992], 70-71 que subjacente a essa discussão se encontra uma diferença de visões de mundo. Aqueles que seguem a Economia Neoclássica são os que aceitam o mercado com base em suas regularidades, com seus resultados totalmente previsíveis; enquanto o Subjetivismo Radical nega a necessidade de qualquer regularidade nas atividades do mercado, implicando que seus resultados sejam completamente imprevisíveis. No pensamento kirzneriano, faltam a essas interpretações o reconhecimento de que há uma propensão econômica a fazer convergir os interesses dos indivíduos, levando a economia em uma determinada direção, mas cujo destino não pode ser previamente conhecido.

5 Em outras palavras, é possível que uma decisão não guarde nenhuma relação com o conjunto de informações objetivas à disposição do empresário naquele momento, sendo seu comportamento determinado exclusivamente pela imaginação criativa que alimenta suas expectativas empresariais. 
No pensamento kirzneriano, a Escola Neoclássica erra ao utilizar o equilíbrio como situação corrente nas discussões sobre a competição de mercado, porque isso depende de os recursos já estarem alocados. Na contramão, Kirzner entende que a teoria da competição deve iniciar com base no desequilíbrio, para explicar como a alocação vai sendo modificada ao longo do tempo por meio da atividade empresarial que descobre oportunidades.

Já o juízo de Kirzner sobre o entendimento do equilíbrio entre os subjetivistas radicais aponta que eles ignoram a possibilidade de usar o equilíbrio como uma ferramenta de análise. Na obra de Kirzner, o estado de coordenação tem o papel instrumental de permitir a discussão dos fenômenos econômicos, simplificando a análise pela adoção do equilíbrio como ponto de referência.

Kirzner (2015a [1985], 146-147) defendeu que a teoria da atividade empresarial por ele apresentada representava um avanço em relação a essas duas possibilidades, porque, no pensamento do autor (e.g. Kirzner, 2018b [1983], 91-92; 2015a [1985], p 146-147), com a admissão do estado de alerta, a função do empresário se torna, simultaneamente, coordenadora do mercado e promotora de inovações. ${ }^{6}$ Desta forma, a ação empresarial faz a economia convergir para uma condição de equilíbrio, mas esta não pode ser definida antecipadamente por estar sujeita aos choques econômicos que os próprios empresários promovem por meio de outras atividades criativas.

A ideia de alerta empresarial associou a novidade que o empresário cria a alguma condição existente no mercado que lhe seja anterior. Seu mérito decorre da identificação de oportunidades ainda não descobertas ou, da mesma forma, da capacidade de antecipá-las a partir das expectativas quanto às condições futuras no mercado. Assim, o sucesso da ação empresarial, representado pela obtenção do lucro puro que a motiva, reflete a maior integração verificada no mercado em razão de o empresário ter coordenado uma situação até então em desequilíbrio, promovendo uma tendência ao equilíbrio (Kirzner, 2015a [1985], 147).

6 O termo "estado de alerta" foi a denominação atribuída por Kirzner à capacidade humana de realizar a função empresarial, ou seja, identificar e aproveitar oportunidades de ganho puro. Isso se manifesta no mercado pela percepção que um agente tem de um diferencial de preços não explicado, existente no presente ou de maneira intertemporal, em que as receitas superam todos os custos envolvidos, incluindo os de oportunidade e os de esforços pessoais, permitindo um lucro puro que pode ser ganho sem nenhuma contrapartida. 


\section{Os argumentos de Kirzner no debate sobre a publicidade na teoria econômica}

Kirzner tentou ao longo da carreira levar as ideias de Mises aos economistas de forma geral. O próprio Kirzner reconheceu que nessa trajetória acabou se direcionando a diferentes auditórios de acordo com o contexto de suas publicações. Jakee e Spong $(2003,478)$ mostraram que isso permite dividir cronologicamente a obra de Kirzner, destacando que, durante a década de 1960 e nos anos 1970, Kirzner esteve mais preocupado em lidar com os problemas que ocupavam o corpo mais geral da profissão. Como esse foi um contexto em que vigorava o uso do agente maximizador robbinsiano, a obra kirzneriana ficou marcada pelo uso de uma noção mais objetiva para o equilíbrio, como se esse pudesse ser determinado, semelhante ao da Economia Neoclássica. ${ }^{7}$

Já no decorrer das décadas de 1970 e 1980, após o aumento da influência de Lachmann sobre a Escola Austríaca, e por meio dele a ampliação de uma visão mais subjetivista nesta corrente, Kirzner passou a destacar a incerteza em seus trabalhos, recorrendo a uma caracterização do estado de equilíbrio mais subjetiva para se aproximar do Subjetivismo Radical. Esse segundo momento, no pós-Revival, é marcado pelo debate interno à Escola Austríaca a que Vaughn (1992, 251; 1994, 114 e 134; 2000, 42) e Barbieri (2001, 120-121; 2008, 119-120 e 128) creditam as diferentes visões acerca do papel do equilíbrio na teoria econômica.

De fato, há indícios nas obras de Kirzner de que ele procurou engajar-se nas discussões da época, desde as mais amplas, como mostrado na introdução deste artigo, até as mais particulares, como se vê em trabalhos específicos publicados pelo autor no início da carreira, em que buscou discutir: o conceito de racionalidade (Kirzner, 1962; 1963b); o crescimento econômico (Kirzner, 1963a); a gestão universitária (Kirzner, 1970); e o papel da propaganda na teoria econômica (Kirzner, 1972; 1975).

Pode-se argumentar que Kirzner expôs a teoria da atividade empresarial no início da carreira em formato e termos mais próximos daqueles utilizados na Economia Neoclássica, e que isso despertou uma série de críticas no

7 Kirzner (2013 [1973], p. 25-26) utilizou o termo "robbinsiano" para se referir ao agente econômico padrão na teoria econômica tradicional, representando um modelo de tomada de decisão cuja função é a maximização de utilidade individual nas escolhas alocativas. No pensamento kirzneriano essa formulação decorre do problema econômico postulado por Lionel Robbins, atender a fins alternativos com base em meios escassos. 
lado Austríaco, mais próximo às interpretações do Subjetivismo Radical. A partir dessa reação, Kirzner viu a necessidade de retomar sua proposição teórica sob um ponto de vista mais subjetivo, realinhando-se à estrutura e conceitos comuns à Escola Austríaca, para sustentar sua interpretação e mantê-la como intermediária em relação ao grau de subjetivismo dessas visões, a Economia Neoclássica e o Subjetivismo Radical.

Essa periodização da argumentação de Kirzner permite definir outro recorte dentro das suas obras, uma divisão de acordo com os dois principais públicos a que ele se dirigiu, considerados em seu pensamento econômico como os casos limites entre os quais sua teoria está posicionada. Levandose em conta que Kirzner publicou textos a respeito da publicidade entre os anos 1960 e 2000, pode-se classificar esses trabalhos a partir da aproximação do autor a cada grupo de acordo com o momento da publicação: em direção à Economia Neoclássica no intervalo entre 1960 e 1980; e ao Subjetivismo Radical entre 1980 e 2000.

Esse debate teórico em economia sobre o papel e os resultados da propaganda ilustra a tentativa de aproximação de Kirzner a audiências específicas. Isso corrobora a possibilidade de classificação da sua obra de acordo com o auditório pretendido pelo uso de determinados argumentos. Com isso, são trazidos novos elementos para qualificar a periodização da obra de Kirzner proposta por Jakee e Spong (2003) mencionada anteriormente.

O tema da publicidade é de especial interesse porque, como será visto, o tratamento dispensado por Kirzner ao tema ilustra a função empresarial na prática. Adicionalmente, o fato de essa discussão ter ocorrido em diferentes momentos e a partir de argumentações distintas, de acordo com a audiência pretendida, Economia Neoclássica ou Subjetivismo radical, permite coletar uma série de aspectos pelos quais o tema ainda é relevante para a teoria econômica.

As seis discussões encontradas na obra de Kirzner acerca da propaganda podem ser classificadas em três contextos: (i) a década de 1970, período em que Kirzner já havia proposto a ideia de função empresarial no processo de mercado, buscando influenciar o auditório da Economia Neoclássica; (ii) a década de 1980, momento em que o autor procura responder à reação dos Austríacos partidários do Subjetivismo Radical; e (iii) o final da década de 1990, quando o debate com o Subjetivismo Radical pode ser considerado próximo do fim. 


\subsection{Década de 1970: ingresso no debate sobre a publicidade e aproximação à Economia Neoclássica}

Segundo Jakee e Spong (2003, 476-478), durante a década de 1970 os trabalhos de Kirzner almejaram a discussão com o mainstream da Economia, principalmente na crítica ao agente econômico robbinsiano. De acordo com Korsgaard et al. $(2016,869)$, quando Kirzner se dedicou à discussão da sua teoria da atividade empresarial frente ao auditório Neoclássico, colocou a ênfase dos seus argumentos na questão do equilíbrio e da tendência a ele.

Tanto o trabalho de Jakee e Spong (2003, 476-477) quanto o de Korsgaard et al. $(2016,869)$ apontam para o fato de a incerteza ter seu peso teórico negligenciado nas obras em que Kirzner escreveu direcionado à audiência da Economia Neoclássica. Destes, o primeiro material que se conhece publicado por Kirzner acerca da publicidade é seu artigo "Advertising" de 1972. O tema foi retratado nessa década, período em que o autor buscava atingir a Economia tradicional, em pelo menos mais três oportunidades: (1) um capítulo do "Competition and Entrepreneurship"; (2) na resenha do livro "Advertising and Society" de Yale Brozen [1974]; e (3) em uma subseção do artigo "Equilibrium versus Market Process".

Como contexto geral desses textos há a declaração do próprio Kirzner de que estava se posicionando em relação a um debate que ele julgou incompleto na época. Kirzner situou sua proposta de revisar o papel da publicidade no sistema econômico motivado pelas interpretações que acreditou equivocadas no período, originadas nas mais distintas visões econômicas (Kirzner, 1972, 515) ou de fora da Economia (Kirzner, 1975). Isso teria permanecido mesmo diante da evolução na discussão da publicidade com a Economia da Informação, que teria mudado o foco da discussão de conteúdo para o papel informacional da propaganda (Kirzner, 2018c [1976], 130).

Entre os equívocos remanescentes estariam a ideia de que a "atividade publicitária" poderia ser: (i) persuasiva, mudando as preferências dos consumidores; ou (ii) uma ferramenta de monopólio; ou ainda (iii) um desperdício de recursos, já que tornaria os produtos mais caros (Kirzner, 1972, 515-516; 1975). ${ }^{8}$

8 O termo "atividade publicitária" foi usado por Kirzner para designar a "atividade empresarial" na realização da propaganda enquanto uma ação do empresário. A forma como ele associou essa ideia em suas respostas a cada uma dessas críticas aqui listadas será vista ao longo do artigo. 
Desta forma, no pensamento kirzneriano, nem mesmo a Economia Neoclássica munida do avanço teórico da Economia da Informação seria suficiente para entender o papel da publicidade na competição do mercado. ${ }^{9}$ Porque quando a Economia Neoclássica assume a hipótese de conhecimento completo, acaba considerando, para Kirzner, uma coordenação tamanha entre os agentes que eles já não são capazes de fazer algo para maior benefício próprio, e isso exclui a noção de rivalidade. A concorrência fica suprimida no equilíbrio porque todos os agentes se encontram plenamente satisfeitos com os resultados alcançados, os melhores que poderiam ter em decorrência das suas preferências e dotação inicial de recursos (Kirzner, 1972, 517-518). Neste cenário não cabe nenhum esforço de venda competitivo entre os ofertantes, porque qualquer iniciativa neste sentido, como é o caso da propaganda, seria inócua (Kirzner, 2013 [1973], 130-131).

O avanço promovido pela Economia da Informação na Economia Neoclássica a que Kirzner se referiu (1972, 522; 2018c [1976], 130-131) também não teria sido capaz, em sua visão, de compreender a verdadeira função da atividade publicitária. Isso porque a propaganda teria sido reinterpretada nessa proposta como forma de diminuir os custos de transferir informações entre demandantes e ofertantes, resolvendo um problema de custos de transação. A leitura kirzneriana sobre essa interpretação é ilustrada pela possibilidade de se separar um produto em duas partes, a mercadoria "de fato" e a informação acerca dela, esta última transmitida pela publicidade. Uma vez que essa informação seria também um produto, poderia ser adquirida de qualquer outro vendedor. Porém, aquele que fornece o produto como um todo, considerado a junção da mercadoria com a informação, estaria em condições de oferecer a parcela informativa a um custo menor. Portanto, na Economia Neoclássica a publicidade é considerada eficiente por representar menores custos na transferência da informação aos consumidores, beneficiando-os.

Disso emerge um dos motivos do descontentamento de Kirzner: "[ $t$ ]he economics of information approach tries to account for the phenomena of advertising entirely in terms of the demand for and supply of nonentrepreneurial knowledge, information that can be bought and sold and even packaged" (Kirzner, 2018c [1976], 130). Uma visão que já inicia in-

9 Esse avanço foi reconhecer que os agentes econômicos diferem em termos da informação que têm disponível, o que ajuda a explicar a diversidade de decisões realizadas no mercado. Porém, mantevese insuficiente por ser dependente da análise de equilíbrio, o que implica a noção de que o agente pode conhecer uma informação que escolheu não adquirir - discussão que será retomada adiante no artigo. 
completa, para Kirzner, por aceitar a ideia de maximização robbinsiana na tomada de decisões (Kirzner, 2018c [1976], 130-131). Então, "[a]s soon as one describes an existing pattern of production as one of disequilibrium; it becomes clear that there exists a dimension for extra-Robbinsian decision-making" (Kirzner, 2013 [1973], 111). Isso porque cabe ao estado de alerta identificar quais as características demandadas pelos consumidores nos produtos existentes no mercado.

Outro motivo da crítica de Kirzner à interpretação oferecida pela Economia Neoclássica é que ela admite a possibilidade de separar os custos de produção e de venda. Nos termos utilizados anteriormente, por considerar factível distinguir com precisão em um produto o que é mercadoria e o que é informação acerca dela. Para Kirzner $(1972,523)$, embora seja possível compreender uma distinção entre mercadoria e informação no mercado, elas são necessariamente complementares como integrantes de um mesmo produto indissociável, porque isolados não têm utilidade para os consumidores. Uma mercadoria que não fosse conhecida não encontraria compradores, enquanto a informação sobre um bem que não existe não serviria para nada. Também por este motivo, para Kirzner (2013 [1973], 114-115), não há como separar custos de produzir e vender porque ambos são esforços de venda, custos que foram assumidos pelo empresário para fornecer um produto e torná-lo conhecido, algo que é do interesse dos consumidores.

Em comum aos dois motivos pelos quais Kirzner considera a Economia Neoclássica incapaz de lidar satisfatoriamente com a atividade publicitária está a admissão que esta corrente faz do estado de equilíbrio. No caso da Economia da Informação, quando descreve a possibilidade de superar a assimetria de informações por meio da publicidade, recorre-se ao suposto de considerar que os indivíduos estão dispostos a pagar por uma informação sem nem mesmo conhecer o seu conteúdo. Neste sentido, há um mercado de informações equilibrado que pode ser tanto causa como consequência do equilíbrio no mercado de produtos, porque ambos decorrem da otimização dos agentes econômicos robbinsianos maximizadores. $\mathrm{Na}$ possibilidade de separar os custos de produção e venda, em que a propaganda torna os agentes mais ávidos pelos produtos, supõe-se a existência de um mercado já equilibrado em que esteja garantida a curva de demanda a partir das preferências dos consumidores. 
Para Kirzner (1975), esses erros interpretativos quanto ao papel da atividade publicitária foram, em grande medida, originados na compreensão equivocada da natureza do processo de mercado. Em Kirzner $(1972,516)$ a propaganda é entendida por seu papel como ferramenta da competição, necessária para o funcionamento do sistema capitalista. Neste cenário, marcado pela imperfeição do conhecimento, praticam-se preços distintos para o mesmo produto. A função empresarial é quem os faz convergir, motivada pelo lucro possível pela exploração desse diferencial de preços.

Assim, Kirzner (2013 [1973], 108) apontou que os próprios empresários competem na realização dessa função, buscando superar-se na busca do lucro puro. Portanto, como em Kirzner (2018c [1976], 130), há na obra deste autor a defesa de que a teoria da atividade empresarial é aquela que se encontra mais preparada para explicar o funcionamento do mercado e, com isso, o papel da propaganda na teoria econômica.

Se a raiz do descontentamento kirzneriano com a interpretação oferecida pela Economia Neoclássica para o papel da publicidade é começar a análise econômica a partir da situação de equilíbrio, a tese da atividade empresarial resolve isso propondo que a economia esteja sempre em desequilíbrio. Em Kirzner (2013 [1973], 110), qualquer situação em que os recursos econômicos poderiam ser realocados para atender melhor a necessidade dos consumidores configura um desequilíbrio, uma falha de coordenação, porque existem oportunidades de ganho não exploradas. Isso ficou ilustrado quando Kirzner (1972, 518-519; 2013 [1973], 108) mostrou que a competição no mercado não se dá apenas por preço, mas também por qualidade, na tentativa de melhor atender aos consumidores na busca pelo lucro.

Então, seguindo o pensamento kirzneriano, vive-se em um mundo onde existem diversas dessas oportunidades de ganho, os lucros puros, embora a maioria das pessoas não perceba. São possibilidades identificadas pelos empresários, que tomam consciência da sua existência e põem em funcionamento a atividade empresarial, a iniciativa de capturá-los (Kirzner, 1972, 525). A existência desse lucro motiva a função empresarial, levando à competição entre diferentes empresários que concorrem pela satisfação dos consumidores das mais variadas formas (Kirzner, 2013 [1973], 108).

Entre as formas de disputa empresarial está a competição via propaganda, uma tentativa de superar a concorrência pela atração da atenção dos consumidores para aquilo que lhes está sendo oferecido (Kirzner, 1975). 
Isso revela o papel da atividade publicitária, enquanto ação empresarial, em dois níveis. No primeiro nível ela leva aos consumidores o conhecimento acerca de um produto existente, tornando-os conscientes da sua existência. Neste sentido, o empresário alivia a necessidade de o consumidor estar alerta às oportunidades de ganho para ele (Kirzner, 1972, 524; 2013 [1973], 108-19; 1975; 2018c [1976], 131). Desta forma, a publicidade cumpre aquele papel informacional destacado na Economia da Informação.

Então, embora se possa distinguir entre as funções de conscientizar um consumidor e fornecer informações (Kirzner, 2013 [1973], 120), há de se considerar que a publicidade faz os dois (Kirzner, 2013 [1973], 124). Porém, no mercado, não há como realizar essas duas atividades de maneira separada, elas resultam conjuntamente da propaganda realizada (Kirzner, 2013 [1973], 125), que o empresário utiliza motivado pelos lucros.

Isso conduz ao segundo nível do papel empresarial da propaganda, como ferramenta competitiva. Neste sentido, é concebida como atividade empresarial realizada para aumentar a concorrência, porque a possibilidade de lucro aguça diferentes empresários em seus estados de alerta. Assim, em uma economia livre, a publicidade atua como instrumento de competição entre eles na disputa pelos ganhos puros, cada um tentando alertar os consumidores sobre o que está sendo oferecido de vantagem em relação aos demais (Kirzner, 1972, 516-517).

Há um resultado que emerge da observação conjunta desses dois níveis em que a atividade publicitária atua. Segundo Kirzner $(1972,517)$, a situação de desequilíbrio é caracterizada pela imperfeição do conhecimento, de modo que a função empresarial reorganiza os recursos econômicos para a maior satisfação dos consumidores. Desta forma, a publicidade não só atende cada consumidor individualmente ao indicar-lhe a existência de uma oportunidade que satisfaça mais aos seus desejos, mas também permite que isso seja feito de maneira econômica pela competição entre empresários.

Kirzner também usou sua teoria da atividade empresarial para responder às críticas direcionadas ao papel publicitário na economia. Um dos ataques considerados por Kirzner (1972, 523-524) refere-se ao caráter persuasivo da propaganda, cuja natureza "chamativa" seria prejudicial. Em especial, segundo Kirzner (1975), porque isso tenderia a ferir a soberania do consumidor, e não promover sua satisfação, já que haveria na publicidade uma 
manipulação do público. Kirzner $(1972,524)$ respondeu que, encarada sob o ponto de vista da necessidade de alertar o consumidor para a existência de um produto, este tem que se fazer conhecido, e por isso há esforços publicitários para atrair a atenção dos consumidores.

Então, se se considera a forma assumida pela publicidade, em Kirzner $(1972,527)$ não se pode prejulgá-la senão como reflexo da própria sociedade, porque a propaganda seria a materialização do tipo e forma de informação que consegue capturar a atenção do estado de alerta daqueles consumidores. De acordo com Kirzner (2013 [1973], 128-129), é possível que a publicidade altere preferências, porque isso muda a percepção acerca do produto oferecido. Mas, isso não seria danoso, seguindo o pensamento kirzneriano, porque mesmo a mensagem mais informativa é uma forma de persuasão à revisão do conhecimento que se tem sobre determinado produto.

Outra crítica importante a que Kirzner se dirigiu foi aquela que considera a publicidade um desperdício de recursos. No pensamento kirzneriano, essa crítica baseia-se na possibilidade de diferenciar custos de produção e venda, já que os gastos publicitários afetam os preços finais, mas não promoveriam melhorias no produto oferecido (Kirzner, 2013 [1973], 132; 1975).

Para responder a isso, Kirzner recuperou sua distinção entre o produtor robbinsiano e o empresário da teoria do processo de mercado, que remetem, respectivamente, às análises econômicas do equilíbrio e do desequilíbrio. Se o mercado for considerado coordenado, como supõe a visão tradicional na admissão da situação de equilíbrio, as informações e oportunidades de lucro já estariam conhecidas. Porém, se se recupera que o mercado está sempre em desequilíbrio, com a competição sendo movimentada pelas tentativas empresariais de antecipar os desejos dos consumidores, a propaganda é tomada como a ferramenta que busca atender esse objetivo (Kirzner, 2013 [1973], 140-142).

Em Kirzner (1972, 526), uma sociedade livre e com abundância de recursos oferece muitas oportunidades, e isso gera um volume de informações que precisa da publicidade para alcançar o conhecimento dos consumidores. No sistema kirzneriano, todos são empresários e competidores condicionados pelo estado de alerta, e por isso usam a publicidade como forma de aproveitar as melhores oportunidades que estão à disposição no mercado. 
A atitude de Kirzner em recuperar as discussões sobre a publicidade ilustra sua busca engajada em participar dos debates com que se deparou, bem como a postura de levar as ideias Austríacas para além dos muros desta Escola. Em especial, nota-se como os textos de Kirzner sobre a atividade publicitária na década de 1970 corroboram a impressão de que a argumentação kirzneriana nesse período é voltada ao diálogo com a Economia Neoclássica, suprimindo-se a incerteza e o caráter criativo da tomada de decisões individual.

No material revisado nesta subseção é possível verificar a preocupação kirzneriana em contestar a lógica da Economia Neoclássica em seus próprios termos, o que é percebido na discussão do real sentido dos conceitos econômicos aí utilizados, como competição, monopólio e curva de demanda.

\subsection{Década de 1980: discutindo a propaganda em meio ao debate com o Subjetivismo Radical}

Como mostraram Vaughn (1992, 251; 1994, 139), Barbieri (2001, 118-119; 2008, 216) e Jakee e Spong (2003, 476-478), na década de 1980 ocorreu um debate interno à Escola Austríaca em que se envolveram Kirzner e Lachmann, este último o principal expoente do Subjetivismo Radical. De acordo com Jakee e Spong (2003, 476-477) e Korsgaard et al. (2016, 871872), a abordagem kirzneriana frente a esse auditório enfatizou a incerteza e seus resultados na economia.

Segundo Korsgaard et al. (2016, 871-872), na discussão com o público Austríaco a argumentação kirzneriana deu destaque ao papel que o empresário realiza na dinâmica econômica, como promotor do processo de mercado. Isso teria sido feito, principalmente, para destacar a propensão à coordenação que existe na economia em razão de a função empresarial permitir explorar oportunidades de lucro ao longo do tempo, possibilitando ao empresário construir o futuro com base nas suas expectativas presentes.

$\mathrm{Na}$ década de 1980, Kirzner voltou a tratar da publicidade na introdução que escreveu ao livro "Advertising and the Market Process: A Modern Economic View", de Robert Ekelund e David Saurman, publicado em 1988. Kirzner (2018a [1988]) nomeou esse texto introdutório de "Advertinsing in a Open-Ended Universe", o que sugere, no uso do termo "Open-Ended", a 
caracterização do tema com base na incerteza. Isso porque Kirzner (1993, 144) afirmou que o conceito é usado para fazer referência à situação de desequilíbrio na economia que decorre de natureza incerta desta. Uma situação em que o processo econômico fica marcado pelo contínuo movimento de tentativa e erro e as mudanças no conhecimento e nas expectativas.

Assim, o uso do referido termo e a ambientação da postura de Kirzner na introdução que ele escreveu podem ser lidos como tentativas de abordar o Subjetivismo Radical, utilizando a ideia de um resultado econômico futuro que está indeterminado no presente. Essa interpretação encontra fundamento em outra possibilidade para a motivação de Kirzner na exposição de suas ideias no texto, não excludente com relação à primeira: a de que o autor estava resgatando maior grau de subjetivismo em seus escritos para analisar o papel da publicidade no processo de mercado, especialmente com relação à Economia Neoclássica.

Com base na introdução escrita por Kirzner (2018a [1988], 246), o livro introduzido por ele foi crítico à centralidade do equilíbrio no tratamento da propaganda pela Economia, entendendo-a a partir da noção de processo, mas teria faltado à obra explorar o lado subjetivo envolvido na discussão, o que Kirzner afirmou querer suprir com sua introdução.

Como todo fenômeno econômico deveria ser analisado com base nas decisões individuais, a falha fundamental atribuída por Kirzner à teoria tradicional no tratamento das atividades publicitárias foi a suposição de que os indivíduos escolhem com base em uma "situação fechada". Com o termo, Kirzner quer apontar que o indivíduo do tipo robbinsiano se depara com opções determinadas externamente, sem possibilidade de criar sua própria escolha. ${ }^{10}$ Neste sentido, a melhor solução já estaria disponível na própria formulação do problema, independente da criatividade empresarial para a superação de dificuldades, bem como supõe que o indivíduo seja capaz de sempre realizar a decisão ótima do ponto de vista alocativo. Isso é derivado, no pensamento kirzneriano, de a teoria econômica tradicional considerar que as decisões dos agentes são condizentes com a condição de equilíbrio, situação em que o resultado das escolhas individuais já está determinado (Kirzner, 2018a [1988], 247).

\footnotetext{
${ }^{10} \mathrm{Ou}$ seja, como se os agentes se deparassem com todas as alternativas predeterminadas, em que lhes cabe apenas o cálculo da melhor via de ação, o que, com base na tese do agente maximizador robbinsiano, implica que sua escolha já esteja determinada.
} 
Quando se admite a indeterminação presente do resultado econômico futuro, entretanto, surge a possibilidade de as atividades individuais serem diferentes daquelas esperadas, porque os agentes exercerão sua criatividade para enfrentar a incerteza inerente ao futuro desconhecido (Kirzner, 2018a [1988], 247-248).

Kirzner (2018a [1988], 248) destacou que a diferença entre as visões que está considerando, "fechada" ou "aberta", é decorrente da quantidade de informações que é previamente assumida na análise econômica. A visão "fechada" corresponde ao sistema determinístico, situação em que há onisciência sobre a existência das informações desejadas, independentemente de terem sido apropriadas ou conhecidas pelos agentes. Estes últimos, uma vez conscientes dessa disponibilidade, podem decidir a melhor via de ação com base na análise de custo-benefício da própria aquisição da informação. Por isso não há surpresa ou especulação na tomada de decisões nessa visão, uma vez que cada resultado possível já foi completamente antecipado. Neste sentido, a informação só tem papel instrumental, ignorando sua substância para a tomada de decisão, uma vez que o indivíduo sabe o que deseja em termos de conhecimento mesmo sem conhecer seu conteúdo. Isso não acontece na visão "aberta" porque "[f]or the open-ended universe it is not enough that knowledge is incomplete; it is required that the decision maker be ignorant of the extent of his own ignorance" (Kirzner, 2018a [1988], 248, ênfase no original).

É por isso que Kirzner (2018a [1988], 248-249) caracterizou todas as decisões no mundo "aberto" como atos criativos, da mesma forma como o são encarados pelo Subjetivismo Radical, porque os resultados de tais ações estarão permanentemente sujeitos a serem incompatíveis com aquilo que era esperado quando das escolhas que lhes originaram. Ou seja, no pensamento kirzneriano as decisões são sempre especulativas porque seus resultados podem não se concretizar como inicialmente imaginado. Por isso a publicidade se impõe, em Kirzner (2018a [1988], 252), como ferramenta de competição aos empresários. Porque, se o futuro é indeterminado, os empresários disputam a atenção dos consumidores que podem não estar informados acerca das oportunidades que lhe estão sendo oferecidas.

Se os agentes não têm ciência do conteúdo da informação disponível, são incapazes de escolher apropriadamente a quantidade dela que deve ser adquirida, como a teoria tradicional espera a partir da Economia da Informação. Da mesma forma, se o mundo é indeterminado, aqueles que 
oferecem alguma coisa ao mercado não tem garantia de que vão conseguir concretizar suas intenções (Kirzner, 2018a [1988], 248-249). Nesta situação entra em cena a necessidade de conectar os diferentes agentes econômicos por meio da informação existente. Aqueles que vendem algo no mercado podem lucrar com essa transmissão de informações, tornando-se auto interessados em sinalizar oportunidades no mercado, e a publicidade cumpre esse objetivo (Kirzner, 2018a [1988], 252). Então, torna-se inerente à função empresarial alertar os potenciais consumidores daquilo que está sendo disponibilizado a eles (Kirzner, 2018a [1988], 248-249). Neste caso, não há como dissociar a oferta de uma oportunidade vantajosa e seu anúncio para os consumidores.

Para Kirzner (2018a [1988], 251), a publicidade não fere as preferências dos consumidores porque, em um mundo indeterminado, a propaganda só está alertando para a existência de informações que podem ter sido negligenciadas pelos agentes econômicos. Uma mudança de preferências só teria sentido na visão determinística do resultado econômico, em que os indivíduos teriam gostos prévios que não se sujeitam a possibilidade de mudança a partir de novo conhecimento. Assim, "[t]he advertiser, it should be emphasized, has not responded to preexisting consumer demand, but neither has he, necessarily, violated that preexisting pattern of demand by invasively altering it through psychological manipulation" (Kirzner, 2018a [1988], 251, ênfase no original).

A postura de Kirzner frente ao papel da publicidade na década de 1980 remete à posição intermediária assumida com relação aos extremos considerados pelo autor, a Economia Neoclássica e o Subjetivismo Radical. A utilização do termo "Open-Ended" no texto resgata a indeterminação dos resultados na economia, sejam eles de decisão individual ou do mercado, mostrando maior subjetivismo com relação aos trabalhos da década de 1970.

Embora Kirzner tenha usado um vocabulário comum ao Subjetivismo Radical, isso não indica uma tentativa de aproximação. Antes, mostra como o debate com o lado mais radical do subjetivismo influenciou a argumentação kirzneriana. A tese de Kirzner se manteve fiel à ligação entre a escolha individual e a realidade objetiva na tomada de decisão, por atribuir ao empresário a exploração de diferenciais de informação por meio das suas tentativas empresariais, permitindo a defesa de uma tendência ao estado de equilíbrio. 
Da mesma forma, foi mantido e acentuado o descontentamento kirzneriano com a Economia Neoclássica. Se o livro introduzido é tomado por uma discussão pouco subjetivista e com uma interpretação da publicidade restrita ao papel de fornecer informações aos consumidores, Kirzner propôs avançar na subjetividade e resgatar o papel concorrencial da propaganda. A crítica à centralidade do equilíbrio na Economia Neoclássica permanece, agora em razão da visão determinista que lhe é atribuída, embora essa também tenha como raiz a distinção entre a tomada de decisão nas versões robbinsiana e misesiana.

Acrescentando o efeito da incerteza na economia, o caráter criativo da atividade publicitária e a diferenciação entre presente e futuro, Kirzner apresentou sob nova ótica alguns aspectos já considerados por ele na década de 1970 sobre a propaganda: a suposição da informação perfeita é revista à luz da falibilidade do conhecimento; a crítica da persuasão é discutida sob o argumento de que os indivíduos podem mudar suas preferências; e a inexistência prévia de uma curva de demanda é reafirmada a partir de um cenário incerto.

Portanto, mesmo Kirzner usando a Economia Neoclássica como pano de fundo de sua abordagem sobre a publicidade, sua argumentação na década de 1980 tomou como base os conceitos utilizados em comum ao Subjetivismo Radical. Isso pode ser interpretado como uma tentativa deliberada de se aproximar dessa abordagem: pelo uso do vocabulário comum; a ênfase no aspecto da indeterminação futura das ações individuais ou dos resultados do mercado; e o caráter criativo da tomada de decisão com base em informações descobertas por meio das ações empresariais. Embora Kirzner tenha continuado a defender a tese da atividade empresarial e a postura crítica à economia tradicional, a argumentação kirzneriana apareceu no texto analisado sob nova roupagem, com linguajar comum aos adeptos do Subjetivismo Radical, mas mantendo uma postura de afastamento em relação a eles.

\subsection{Década de 1990: a atividade publicitária no pós-debate com o Subjeti- vismo Radical}

Embora Jakee e Spong (2003, 476-478) situem a preocupação kirzneriana em debater com o Subjetivismo Radical no período entre 1970 e 1980, a 
década de 1990 é nitidamente marcada por esse debate. Como reconheceu Kirzner (e.g. Boettke e Sautet, 2018, 744-745), houve neste período o uso de uma argumentação diferenciada, aquela em termos de Variáveis Subjacentes e Variáveis Induzidas decorrente do debate Austríaco sobre a natureza do equilíbrio. ${ }^{11}$ De fato, Kirzner (1992b, ix) fez referência direta a essa discussão no prefácio de seu livro de 1992, apontando que a obra tinha como objetivo mostrar o porquê de a visão Austríaca compreender a tendência ao equilíbrio econômico. Assim, apareceu neste livro a postura kirzneriana de considerar a Escola Austríaca como proposta intermediária entre os extremos representados pela Economia Neoclássica e pelo Subjetivismo Radical (e.g. Kirzner, 1992b; Moser, 1992; Robertson, 1993; Blaug, 1993).

Na década de 1990, portanto, ainda existia alguma influência do debate com o Subjetivismo Radical sobre o pensamento econômico kirzneriano, principalmente à luz da perspectiva pós-Revival em que diferentes personagens tentaram definir uma agenda de pesquisa para a Escola Austríaca. É provável que essa discussão estivesse arrefecida na década de 1990 por dois motivos. O primeiro é a publicação do livro de O'Driscoll e Rizzo em 1985 que fez grande sucesso entre os adeptos da Escola Austríaca por unificar as ideias de Kirzner e Lachmann. ${ }^{12}$

O segundo motivo é a morte de Lachmann ter ocorrido em 1990, já que foi com base no pensamento lachmaniano que ganhou força o movimento subjetivista radical na Escola Austríaca. Este personagem fora o principal debatedor das ideias de Kirzner, entre os Austríacos, acerca do processo de mercado nas décadas de 1970 e 1980. Ambos discutiram a existência de uma tendência ao equilíbrio na competição de mercado, traduzindo um debate mais profundo acerca do grau de subjetivismo a ser admitido na teoria econômica, posições individuais que ilustram os diferentes caminhos para a agenda de pesquisa que tomava forma no pós-Revival e foi denominada de Moderna Escola Austríaca.

${ }^{11}$ Kirzner chamou de Variáveis Subjacentes as preferências, disponibilidade de recursos e tecnologias, ou seja, variáveis que determinam as decisões individuais. Como Variáveis Induzidas foram tomados os preços, métodos de produção, quantidade e qualidade dos produtos, ou seja, variáveis que são determinadas no mercado. Na lógica kirzneriana as Variáveis Subjacentes determinam as Variáveis Induzidas (Kirzner, 1992a [1990], p. 42).

12 "The Economics of Time and Ignorance", cuja publicação foi considerada por Vaughn (1992, p. 251252; 1994, p. 135-137; 2000, p. 43) e Barbieri (2001, p. 119-120; 2008, p. 228) uma tentativa de conciliar as visões kirzneriana e lachmaniana naquele debate entre os Austríacos sobre o processo de mercado na década de 1980 . 
Na década de 1990 houve nova tentativa de Kirzner em expor sua visão empresarial sobre a publicidade, em uma seção sobre o tema em seu livro "How Markets Work" de 1997. Kirzner (1997a, 54), retomando a dificuldade de o papel da publicidade ser assimilado nos modelos de competição da teoria tradicional, caracterizou o erro dessa abordagem em dois pontos. No primeiro está o fato de a propaganda nessa visão ser identificada como um conjunto de gastos com o objetivo de influenciar a curva de demanda por meio da mudança nas preferências dos consumidores. Isso posto, a atividade publicitária estaria interpretada como um fator de custo que afeta o preço da mercadoria, de modo que os consumidores estariam pagando pela própria manipulação a que estão sujeitos.

O segundo ponto destacado por Kirzner (1997a, 56) foi a admissão da existência de uma curva de demanda prévia, que torna necessário considerar que o consumidor participe do mercado com base em preferências predeterminadas. Ou seja, os gostos seriam anteriores à própria participação no mercado, preconcebidos independentemente daquilo que está sendo anunciado pelos ofertantes. Assim, somente quando da incapacidade dos vendedores em atender a essa demanda há uma falha de mercado, porque a publicidade não estaria cumprindo adequadamente seu papel de levar a informação, enquanto produto, aos seus demandantes.

Essas duas visões atribuídas à Economia Neoclássica por Kirzner (1997a, 55) foram consideradas equivocadas, principalmente por se basearem no entendimento de que toda informação seja comercializável, uma visão incapaz de perceber os elementos que relacionam a publicidade e a persuasão dos consumidores por meio da atividade publicitária em sua essência competitiva. Como solução para essas deficiências interpretativas, Kirzner (1997a, 57) propôs interpretar a propaganda por meio de sua teoria da atividade empresarial.

Kirzner (1997a, 55) mostrou como a teoria Austríaca faz mais do que considerar o aspecto informacional da publicidade, lembrando que o conhecimento pode existir sem que se tenha consciência dele. Nesta interpretação, a atividade publicitária é vista como uma sinalização desse conhecimento, em sentido mais próximo de alertar os consumidores do que de mudar suas preferências. Principalmente porque, na interpretação de Kirzner (1997a, 56), a curva de demanda não pode ser assumida como preexistente, como se os consumidores já soubessem suas preferências. Neste caso, a publicidade deveria ser reconhecida como expressão da inovação realizada 
pelo empresário ao criar uma novidade à disposição do consumidor, já que para este último o produto só pode existir quando se está consciente dele.

No pensamento kirzneriano, a visão Austríaca é capaz de incorporar a publicidade por entender que ela se rende à soberania do consumidor, mais inclinada a atender suas preferências do que o persuadir. Essa interpretação afasta as críticas de que a publicidade visa manipular o consumidor, porque, se a atividade publicitária é interpretada como forma de alertá-lo para oportunidades de consumo já existentes, ela torna-se imune à divisão objetiva entre a transmissão de informação e a persuasão (Kirzner, 1997a, $56)^{13}$

Diferente dos textos publicados nas décadas anteriores, a argumentação utilizada em 1997 não se prendeu exclusivamente àquela relacionada à Economia Neoclássica ou ao Subjetivismo Radical. Ela esteve voltada a ser intermediária, embora mais próxima do discurso realizado junto à Economia Neoclássica, porque esse é um estilo argumentativo que Kirzner utilizou em boa parte da sua obra geral como forma de engajamento, buscando comparar sua posição à teoria econômica tradicional em linguagem comum à profissão.

Nesse texto sobre a publicidade de 1997, conquanto Kirzner tenha repetido a estratégia de aproximar seu vocabulário daquele utilizado no corpo mais amplo da Economia, ainda há o uso da atividade empresarial em seu sentido mais subjetivo. Isso é visto na recuperação do caráter inovativo do papel empresarial de oferecer novas oportunidades no mercado, na falibilidade do conhecimento, no estado de alerta como uma espécie de percepção sensorial, na reafirmação da inexistência de uma curva de demanda prévia na economia e na discussão do papel e conteúdo da informação. Logo, no texto analisado parece não existir uma inclinação da argumentação de Kirzner para um auditório específico, apenas a busca em apresentar a publicidade a partir da teoria da atividade empresarial.

${ }^{13}$ Fazendo referência ao mundo real, Kirzner (1997a, p. 57) destacou dois pontos para reforçar sua posição: (i) existe a necessidade empresarial de tornar os consumidores conscientes daquilo que não sabem; (ii) os vendedores irão preferir se esforçar, por meio da propaganda, na venda de algo que os consumidores querem, ao invés de tentar convencê-los a consumir algo que inicialmente não desejam. 


\section{Considerações finais}

Com base na revisão de dois debates gerais que estão compreendidos na trajetória de Kirzner, com o grupo mais largo da profissão dos economistas e com os seguidores do Subjetivismo Radical próximos da Escola Austríaca, foram resgatados os argumentos de Kirzner a partir de suas discussões sobre a propaganda na teoria econômica.

O estudo da discussão kirzneriana sobre a publicidade permitiu mostrar como Kirzner buscou levar seu posicionamento às diferentes audiências a que se dirigiu. Foi possível mostrar como a argumentação de Kirzner mudou cronologicamente, influenciada pelas distintas preocupações teóricas do autor em cada época: influenciar a Economia Neoclássica ou o Subjetivismo Radical acerca da relevância da teoria empresarial do processo de mercado. Kirzner se direcionou de maneira particularizada às audiências pretendidas na tentativa de levar suas ideias a elas, e não para incluir-se entre tais grupos porque, embora use termos comuns a eles, isso foi feito para demarcar uma posição diferenciada.

Como visto, Kirzner não mudou sua teoria para fazê-la caber no arcabouço da Economia Neoclássica ou do Subjetivismo Radical. Antes, o que ele fez foi moldar a apresentação da teoria da atividade empresarial para mostrar pontos de convergência e divergência entre as propostas, mostrando a realização da função empresarial como um avanço teórico no entendimento do processo decisório. Em especial, o presente artigo mostrou como isso foi feito para a propaganda, tema inicialmente debatido por Kirzner na década de 1970 e posteriormente resgatado nas décadas de 1980 e 1990. 


\section{Referências}

Barbieri, Fabio. 2001. "O Processo de Mercado na Escola Austríaca Moderna." Dissertação de Mestrado, Departamento de Economia, Faculdade de Economia, Administração e Contabilidade, Universidade de São Paulo.

Barbieri, Fabio. 2008. "O Ressurgimento da Escola Austríaca e a Teoria de Processo de Mercado." Revista Econômica, 10 (2): 215-235.

Blaug, Mark. 1993. "Resenha do livro The Meaning of Market Process: Essays in the Development of Modern Austrian Economics, por Israel M. Kirzner (1991).” The Economic Journal 103 (418): 757-758.

Boehm, Stephan. 1992. "Austrian Economics and the theory of entrepreneurship: Israel M. Kirzner interviewed by Stephan Boehm on 2 May 1989.” Review of Political Economy 4 (1): 95-110.

Boettke, Peter J. 1995. "Resenha do livro Classics in Austrian Economics, 3 volumes, editado por Israel M. Kirzner (1994)." The Freeman: 134-135.

Boettke, Peter J. 2014. "Entrepreneurship and the entrepreneurial market process: Israel M. Kirzner and the two levels of analysis in spontaneous order studies." Review of Austrian Economics 27: 233-247.

Boettke, Peter J., e Frédéric E. Sautet, ed. 2009. The Collected Works of Israel M. Kirzner: The Economic Point of View: An Essay in the History of Economic Thought. Vol. 1. Indianapolis: Liberty Fund.

Boettke, Peter J.; Sautet, Frédéric E. ed. 2010. The Collected Works of Israel M. Kirzner: Essays on Capital and Interest: An Austrian Perspective, Vol. 2. Indianapolis: Liberty Fund.

Boettke, Peter J., e Frédéric E. Saute. 2018. “A Conversation with Israel Kirzner, July 2006, by Peter J. Boettke and Frédéric Sautet." In The Collected Works of Israel M. Kirzner: Reflections on Ethics, Freedom, Welfare Economics, Policy, and the Legacy of Austrian Economics, editado por Boettke, P. J., e F. E. Sautet, vol. 9, 725-761. Camel: Liberty Fund.

Caldwell, Bruce J. 1984, "Resenha do livro Method, Process, and Austrian Economics: Essays in Honor of Ludwig von Mises, editado por Israel M. Kirzner (1982)". Southern Economic Journal 50 (4): 1234-1236.

Garrison, Roger W. 2002. "Capital, Interest, and Professor Kirzner." Journal des Economistes et des Etudes Humaines 12 (2): 343-356.

Jakee, Keith, e Heath Spong. 2003. "Praxeology, entrepreneurship and the market process: A review of Kirzner's contribution." Journal of the History of Economic Thought 25 (4): 461-486.

Kirzner, Israel M. "Rational action and economic theory." 1962. Journal of Political Economy 70 (4): 380-385.

Kirzner, Israel M. 1963a. "On the Premises of Growth Economics." New Individualist Review 3 (1): 20-28.

Kirzner, Israel M. 1963b. "Rational Action and Economic Theory: Rejoinder." Journal of Political Economy 71 (1): 84-85.

Kirzner, Israel M. 1970. “The "POWER" Problem on Campus: An Economist's View.” Intercollegiate Review 6 (3): 99-103.

Kirzner, Israel M. 1972. “Advertising.” The Freeman 22 (9): 515-528.

Kirzner, Israel M. 1975. "Resenha do livro Advertising and Society, editado por Yale Brozen (1974)]." Reason. Disponível em: http://reason.com/archives/1975/11/01/advertising-and-society. Acesso em 24/05/2020.

Kirzner, Israel M. 1992a [1990]. "The meaning of market process." In The meaning of market process: Essays in the development of modern Austrian economics, 38-54. London: Routledge.

Kirzner, Israel M. 1992b. The meaning of market process: Essays in the development of modern Austrian economics. London: Routledge.

Kirzner, Israel M. 1993. "Resenha do livro Welfare Economics and Externalities in an Open-Ended Universe: A Modern Austrian Perspective, por Roy E. Cordato (1992).” Cato Journal, 13 (1): 143-149.

Kirzner, Israel M. 1997a. How markets work: Disequilibrium, entrepreneurship and discovery. London: The Institute of Economic Affairs. 
Kirzner, Israel M. 1997b. "The Kirznerian Way: An interview with Israel M. Kirzner.” Austrian Economic Newsletter 17 (1):1-8.

Kirzner, Israel M. 2013 [1973] “Competition and Entrepreneurship.” In The Collected Works of Israel M. Kirzner: Competition and Entrepreneurship, editado por Boettke, P. J., e F. E. Sautet, vol. 4, 1-200. Indianapolis: Liberty Fund.

Kirzner, Israel M. 2015a [1985]. "Entrepreneurship, Economics and Economists." In The Collected Works of Israel M. Kirzner: Austrian Subjectivism and the Emergence of Entrepreneurship Theory, editado por Boettke, P. J, e F. E. Sautet, vol. 5, 139-150. Indianapolis: Liberty Fund.

Kirzner, Israel M. 2015b [1992]. "Subjectivism, Freedom and Economic Law." In The Collected Works of Israel M. Kirzner: Austrian Subjectivism and the Emergence of Entrepreneurship Theory, editado por Boettke, P. J., e F. E. Sautet, vol. 5, 111-120. Indianapolis: Liberty Fund.

Kirzner, Israel M. 2016 [1989]. "Discovery, Capitalism and Distributive Justice." In The Collected Works of Israel M. Kirzner: Discovery, Capitalism, and Distributive Justice, editado por Boettke, P. J., e F. E. Sautet, vol. 5, 1-196. Indianapolis: Liberty Fund.

Kirzner, Israel M. "Advertising in an Open-Ended Universe." 2018a [1988]. In The Collected Works of Israel M. Kirzner: Competition, Economic Planning, and the Knowledge Problem, editado por Boettke, P. J., e F. E. Sautet, vol. 7, 246-253. Indianapolis: Liberty Fund.

Kirzner, Israel M. "Entrepreneurship and the Future of Capitalism." 2018b [1983]. In The Collected Works of Israel M. Kirzner: The Essence of Entrepreneurship and the Nature and Significance of Market Process, editado por Boettke, P. J., e F. E. Sautet, vol. 8, 82-97. Carmel: Liberty Fund.

Kirzner, Israel M. "Equilibrium versus Market Process." 2018c [1976]. In The Collected Works of Israel M. Kirzner: The Essence of Entrepreneurship and the Nature and Significance of the Market Process, editado por Boettke, P. J., e F. E. Sautet, vol. 8, 125-133. Carmel: Liberty Fund.

Korsgaard, Steffen, Henrik Berglund, Claus Thrane, e Per Blenker. 2016. "A tale of two Kirzners: Time, uncertainty, and the "nature" of opportunities." Entrepreneurship Theory and Practice 40 (4): 867-889.

Moser, Peter. 1992. "Resenha do livro The Meaning of Market Process: Essays int the Development of Modern Austrian Economics, por Israel M. Kirzner (1992)." Journal of Institutional and Theoretical Economics 148 (4): 721-722.

Robertson, Paul L. 1993. "Resenha do livro The Meaning of Market Process: Essays int the Development of Modern Austrian Economics, por Israel M. Kirzner (1992)." History of Political Economy 25 (3): 557-558.

Vaughn, Karen I. 1992. "The problem of order in Austrian economics: Kirzner vs. Lachmann." Review of Political Economy 4 (3): 251-274.

Vaughn, Karen I. 1994. Austrian Economics in America: The Migration of a Tradition. Cambridge: Cambridge University Press.

Vaughn, Karen I. 2000. “The rebirth of Austrian economics: 1974-99.” Economic Affairs 20 (1): 40-43. 